\title{
Abordagem integrada da saúde bucal de droga-dependentes em processo de recuperação ${ }^{\dagger}$
}

\section{Integrated approach to the oral health of drug-addicted undergoing rehabilitation}

\author{
Érica Del Peloso Ribeiro* \\ Jonas Alves de Oliveira* \\ Andressa Pelissari Zambolin* \\ José Roberto Pereira Lauris** \\ Nilce Emy Tomita**
}

\begin{abstract}
RESUMO: No atual contexto de uso crescente e precoce de drogas (fármacos recreacionais), legais ou não, a finalidade deste trabalho foi avaliar as condições de saúde bucal de 102 indivíduos, do sexo masculino, da instituição de recuperação Esquadrão da Vida, em Bauru - SP. O diagnóstico desta condição foi feito por meio da experiência de cárie (CPOD), placa bacteriana (PHP), índice gengival e teste de fluxo salivar. Objetivou-se também a implantação e verificação da eficácia de um programa educativo-preventivo. A idade média dos internos foi de 29,17 anos $(\mathrm{dp}=11,40 ; \mathrm{n}=95)$. Dos internos ( $\mathrm{n}=102), 72,54 \%$ tinham o hábito de comer entre as refeições e $69,60 \%$ não utilizavam fio dental. O CPOD observado foi de $14,88(\mathrm{dp}=6,38 ; \mathrm{n}=86) \mathrm{e}$, quando correlacionado à idade, obteve-se $\mathrm{r}=0,55(\mathrm{p}<0,001$ - estatisticamente significante). O PHP inicial foi de $2,34(\mathrm{dp}=0,69 ; \mathrm{n}=14) \mathrm{e}$, decorridos 3 meses, reduziu para $1,91(\mathrm{dp}=0,74 ; \mathrm{n}=14)$. O fluxo salivar inicial foi de $1,31 \mathrm{ml} / \mathrm{min}(\mathrm{dp}=0,7 ; \mathrm{n}=97)$, sendo apenas 13 reavaliados após 3 meses, devido à flutuação deste grupo populacional, obtendo-se $1,13 \mathrm{ml} / \mathrm{min}(\mathrm{dp}=0,49)$. O indice gengival e o PHP iniciais apresentaram $\mathrm{r}=0,30(\mathrm{p}=0,002-$ estatisticamente significante). A necessidade objetiva de tratamento verificada e a importância subjetiva conferida à saúde bucal apresentaram correlação negativa ( $r=-0,26 ; p=0,019$ - estatisticamente significante), indicando que a valorização da saúde bucal repercute sobre os cuidados em saúde e tem reflexos sobre o processo saúde-doença bucal.
\end{abstract}

UNITERMOS: Centros de tratamento de abuso de substâncias; Estudos epidemiológicos; Educação em saúde bucal; Prevenção \& controle; Saliva.

\begin{abstract}
Considering the current context of increasing and early utilization of licit or illicit drugs (habit-forming substances), the aim of this study was to evaluate the oral health conditions of 102 males from the Esquadrão da Vida rehabilitation center, in Bauru, São Paulo, Brazil. The evaluation was carried out by means of the assessment of caries experience (DMFT), dental plaque (PHP), gingival index and salivary flow. This study also aimed at instituting an educational-preventive program and evaluating its efficacy. The subjects' mean age was 29.17 years $(\mathrm{sd}=11.40 ; \mathrm{n}=95)$. From all subjects $(n=102), 72.54 \%$ had the habit of eating between meals, and $69.60 \%$ did not utilize dental floss. The observed DMFT was $14.88(\mathrm{sd}=6.38 ; \mathrm{n}=86)$. The initial PHP was $2.34(\mathrm{sd}=0.69 ; \mathrm{n}=14)$ and, after 3 months, it was reduced to 1.91 ( $\mathrm{sd}=0.74 ; \mathrm{n}=14)$. The initial salivary flow was $1.31 \mathrm{ml} / \mathrm{min}$ ( $\mathrm{sd}=0.7 ; \mathrm{n}=97)$. Due to the fluctuation of this group, only 13 of the original subjects were reevaluated after 3 months, when a salivary flow of $1.13 \mathrm{ml} / \mathrm{min}$ $(\mathrm{sd}=0.49)$ was registered. The initial gingival index and PHP presented $\mathrm{r}=0.30(\mathrm{p}=0.002-$ statistically significant) . The objective need for treatment and the subjective importance given to oral health were negatively correlated $(\mathrm{r}=-0.26 ; \mathrm{p}=0.019$ - statistically significant), which indicates that the value attributed to oral health influences health care and affects the oral health-sickness process.
\end{abstract}

UNITERMS: Substance abuse treatment centers; Epidemiologic studies; Dental health education; Prevention \& control; Saliva.

\section{INTRODUÇÃO}

Os drogaditos constituem uma classe de pacientes especiais pouco estudada, com escassez de dados precisos sobre a realidade do consumo de drogas, apesar do crescente aumento deste fenômeno social. Isso contribui para que cirurgiõesdentistas e outros profissionais da Saúde desconheçam como atuar sobre essa parcela da população. Friedlander, Mills ${ }^{7}$ (1985) observaram que os

$\dagger$ Apoio: PIBIC/CNPq.

*Acadêmicos do Curso de Graduação em Odontologia; **Professores Doutores do Departamento de Odontopediatria, Ortodontia e Saúde Coletiva - Faculdade de Odontologia de Bauru da Universidade de São Paulo. 
Ribeiro EDP, Oliveira JA de, Zambolin AP, Lauris JRP, Tomita NE. Abordagem integrada da saúde bucal de droga-dependentes em processo de recuperação. Pesqui Odontol Bras 2002;16(3):239-245.

consumidores de drogas são pessoas jovens, com idade variando entre 15 e 35 anos.

Bullock $^{2}$ (1999) define drogas como substâncias que afetam tanto o sistema nervoso central quanto a percepção que o indivíduo tem do meio. A partir desse conceito, Meechan ${ }^{10}$ (1999) relatou alguns sinais associados ao uso de drogas, como alterações de humor, perda da vaidade e uso desproporcional de analgésicos.

A própria condição bucal pode apresentar características peculiares. Segundo Pedreira et al. ${ }^{16}$ (1999), os principais achados em pacientes que usam drogas são: xerostomia, CPOD elevado, redução da capacidade tampão da saliva, queilite angular, bruxismo, perdas dentais, doença periodontal, halitose e estomatites.

Os fatores etiológicos são descritos na literatura especializada, de modo a justificar a precária condição de saúde bucal dos drogaditos. Di Gugno et al..$^{5}$ (1981) consideram três os principais fatores: redução do $\mathrm{pH}$ e fluxo salivar, baixa concentração de fosfato inorgânico, que dificulta a remineralização e alto consumo de carboidratos refinados. Kranzer et al. ${ }^{8}$ (1989) e Dunkley, Carson ${ }^{6}$ (1968) citam também a má higiene bucal relacionada à baixa auto-estima e falta de motivação. Ressalta-se ainda que algumas drogas apresentam efeitos anestésicos, minimizando ou eliminando a dor, que constitui um sinal de alerta para que se procure o cirurgião-dentista.

A redução do fluxo salivar é explicada no caso da maconha por Darling, Arendorf ${ }^{4}$ (1992) em função da ação parassimpatolítica da droga. Esse e os outros fatores etiológicos embasam a verificação da alta prevalência de cárie e doença periodontal em droga-dependentes ${ }^{1}$.

Miers, Smith ${ }^{11}$ (1989) relataram a importância de avaliar, além dos drogaditos ativos, a população de droga-dependentes em processo de recuperação, dividida entre os que já haviam retornado ao convivio social e aqueles que ainda estavam nas clínicas de recuperação. Sugerem que o cirurgião-dentista deve questionar se o paciente está se recuperando de dependência química e em caso afirmativo, evitar drogas que provoquem alterações de humor.

No processo de recuperação, os drogaditos com freqüência utilizam tranqüilizantes, como a clorpromazina, citada por Scopp et al. ${ }^{14}$ (1965), para tratamento da ansiedade, agitação e alucinações, ajudando na capacidade de o paciente responder à psicoterapia. Essa droga, por ser um agente paras- simpatolítico, tem como principal efeito adverso a xerostomia.

Apesar destes estudos, pouco se fez sobre a proposta de Scheutz ${ }^{13}$ (1984), de avaliar o efeito de um programa de saúde bucal em drogaditos em recuperação. Com este objetivo, Tomita, Consulin ${ }^{18}$ (2000) estabeleceram um programa educativo em uma instituição de recuperação de droga-dependentes. O programa causou redução da placa bacteriana para os alunos e funcionários, com melhores resultados no primeiro grupo. Este dado reforça a importância do autocuidado durante o processo de recuperação e a importância de programas de saúde destinados a esse grupo social.

A Odontologia, além de aliviar a dor, pode contribuir para a reabilitação desses pacientes, auxiliando no desenvolvimento da auto-estima e ampliando a interação social, já que a recuperação implica o resgatar do ser humano em todos os aspectos, eliminando o significado psicológico das drogas.

Em função disso, esse estudo tem como objetivos: 1) traçar o perfil das condições de saúde bucal de drogaditos em recuperação, matriculados no Esquadrão da Vida, Bauru - SP; 2) verificar a eficácia de um programa preventivo-educativo, embasado nos conceitos de valorização da saúde bucal para indivíduos em processo de recuperação de dependência química; 3) verificar a condição objetiva de saúde bucal frente à subjetividade dos valores conferidos à mesma e 4) observar se o processo de recuperação tem influência sobre o fluxo salivar.

\section{MATERIAIS E MÉTODOS}

Este estudo foi realizado em uma instituição de caráter filantrópico para recuperação de droga-dependentes, o Esquadrão da Vida, localizada na zona rural do município de Bauru - SP. A equipe de trabalho dessa instituição é composta por pastores, teólogos, psicólogos e pessoal de apoio. A internação é voluntária e o tratamento tem duração de seis meses. Neste período, é realizada a desintoxicação com boa alimentação, esportes e laborterapia, permitindo que a recuperação ocorra no âmbito físico, espiritual, psicológico e social.

Foram examinados 102 internos, do sexo masculino, em recuperação de dependência química, constituindo um estudo longitudinal, com 12 meses de duração. Durante este período, foram realizadas visitas mensais à população. 
Ribeiro EDP, Oliveira JA de, Zambolin AP, Lauris JRP, Tomita NE. Abordagem integrada da saúde bucal de droga-dependentes em processo de recuperação. Pesqui Odontol Bras 2002;16(3):239-245.

Respeitando-se o protocolo de pesquisa aceito pelo comitê de ética da instituição - FOB/USP, anteriormente às avaliações, cada indivíduo firmou seu consentimento de participar no projeto pela assinatura do termo de consentimento livre e esclarecido, após receber a carta de informação ao paciente. Receberam em seguida dois questionários: o primeiro para avaliação das noções de higiene bucal, padrão de alimentação, grau de importância da saúde bucal e interesses gerais, para melhor direcionamento das atividades realizadas, e o segundo questionário (OIDP) referiu-se à satisfação com a saúde bucal dos internos.

O diagnóstico das condições de saúde bucal foi realizado por meio do CPOD $\left(\mathrm{OMS}^{20}, 1997\right)$, índice PHP ("patient hygiene performance" - Podshadley, Halley $\left.{ }^{17}, 1968\right)$, IG (indice gengival - Löe $\left.{ }^{9}, 1967\right)$ e teste de fluxo salivar. Na realização destes levantamentos, os instrumentos usados no exame clínico foram espelhos bucais e sondas CPI $\left(\mathrm{OMS}^{20}, 1997\right)$ previamente esterilizados. Para o PHP foram utilizadas também pastilhas evidenciadoras de placa. A iluminação foi a natural e o registro dos dados feito em fichas individuais.

A partir de metodologia participativa, foram desenvolvidas mensalmente atividades de educação em saúde bucal e de motivação ao autocuidado, objetivando-se ensinar como realizar uma boa higiene bucal, através de correta escovação e uso do fio dental. Temas como cárie, doença periodontal e importância da prevenção também foram abordados. Nas palestras, quadros explicativos e macromodelos foram utilizados como material de apoio.

Ao final das reuniões, atividades participativas como jogos de mímica, gincana e palavras cruzadas foram desenvolvidas, buscando-se consolidar os conceitos ensinados. Como estímulo à participação, houve sorteio de prêmios como camisetas, bonés e chaveiros. Esses momentos de integração geraram estímulos de valorização à saúde bucal e promoção dos cuidados de higiene.

A cada visita, foi aplicado o PHP e o IG. Este avalia as mudanças qualitativas na gengiva, enquanto o PHP verifica a eficácia de um programa preventivo, pois fornece dados relativos à presença de placa nos dentes do paciente.

Para obtenção do fluxo salivar, a saliva estimulada foi obtida por mastigação de um pedaço de borracha, de cerca de $1 \mathrm{~cm}$. O paciente o mastigou, por um minuto, e a saliva produzida foi desprezada. Nos cinco minutos seguintes, o paciente dispensou a saliva produzida em um recipiente, iden- tificado com seu nome. Dividindo-se a quantidade de saliva formada ( $\mathrm{ml}$ ) pelo tempo gasto (minutos), obteve-se a secreção salivar em $\mathrm{ml} /$ minuto.

Feita a coleta de dados, os achados obtidos foram processados e analisados, através de testes estatísticos (análise de variância; coeficiente de correlação de Pearson), visando testar as associações propostas.

\section{RESULTADOS}

No período de agosto de 2000 a julho de 2001, 102 individuos foram avaliados, sendo a totalidade do grupo composto por internos em recuperação. A constatação da não-participação dos funcionários da instituição ocorreu no decorrer do estudo. As recusas foram motivadas em especial por tratar-se do segundo ano de desenvolvimento do programa.

Ao contrário do grupo-teste, que apresenta elevada flutuação, o grupo de funcionários é parte integrante da população fixa da instituição. Sendo assim, sua participação no projeto ocorreu no período de agosto de 1999 a julho de 2000. Estas recusas foram respeitadas, de forma que, na apresentação dos resultados, não haverá grupo controle.

Os participantes eram predominantemente jovens, sendo que a média de idade da população foi de 29,17 anos (dp = 11,40; $\mathrm{n}=95$ ) (Gráfico 1).

Verificou-se um baixo nível de escolaridade, sendo predominante o número de indivíduos que não completaram o primeiro grau $(29,71 \%)$. Ao serem questionados sobre os hábitos alimentares, dos $72,54 \%$ que relataram apresentar o hábito de comer entre as refeições, $37,74 \%$ comiam balas, chicletes e chocolates.

Com relação à higiene bucal, 41,17\% afirmaram escovar os dentes três vezes ao dia. A maioria

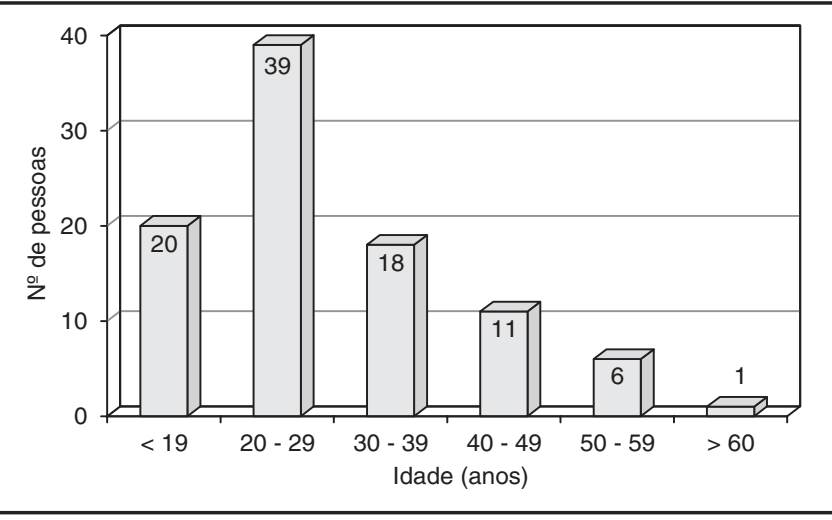

GRÁFICO 1 - Distribuição da amostra segundo a idade. Bauru - SP, 2000-2001. 
Ribeiro EDP, Oliveira JA de, Zambolin AP, Lauris JRP, Tomita NE. Abordagem integrada da saúde bucal de droga-dependentes em processo de recuperação. Pesqui Odontol Bras 2002;16(3):239-245.

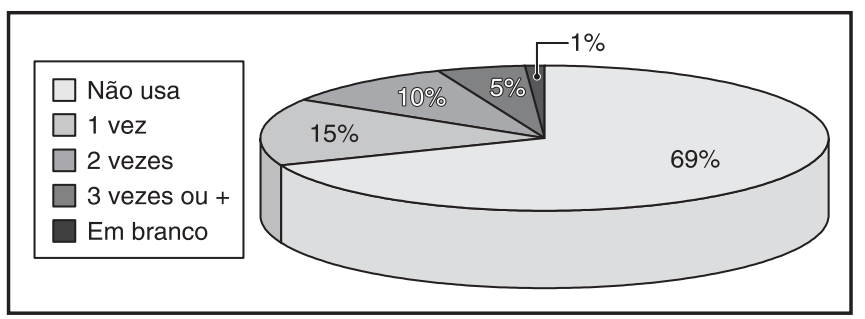

GRÁFICO 2 - Distribuição da amostra quanto ao uso diário do fio dental. Bauru - SP, 2000-2001.

TABELA 1 - Evolução do índice de placa bacteriana (PHP). Bauru - SP, 2000-2001.

\begin{tabular}{c|c|c}
\hline \hline Exame & PHP & $\mathrm{n}$ \\
\hline $1^{\mathrm{o}}$ & 2,29 & 99 \\
\hline $2^{\mathrm{o}}$ & 2,01 & 54 \\
\hline $3^{\mathrm{o}}$ & 2,16 & 31 \\
\hline $4^{\circ}$ & 1,91 & 14 \\
\hline $5^{\circ}$ & 2,50 & 6 \\
\hline $6^{\circ}$ & 3,16 & 1 \\
\hline \hline
\end{tabular}

$(69,60 \%)$ dos examinados não utilizava o fio dental (Gráfico 2).

Parte dos internos $(31,37 \%)$ havia ido pela última vez ao dentista há mais de vinte e quatro meses, embora $38,23 \%$ tenham relatado que estiveram em consulta odontológica há menos de seis meses.

Verificou-se CPOD de 14,88 (dp = 6,38; $\mathrm{n}=86)$ com média da necessidade de tratamento odontológico de 6,72. Correlacionou-se a idade ao CPOD de forma positiva $(\mathrm{r}=0,55, \mathrm{p}=0,001$ - estatisticamente significante) (Gráfico 3).

$\mathrm{O}$ primeiro exame coincidiu com a entrada do interno no programa e o PHP foi 2,29 (n = 99) e o IG $0,78(\mathrm{n}=100)$. No sexto e último exame, obteve-se $3,16(\mathrm{n}=01)$ e $0,41(\mathrm{n}=01)$, respectivamente $(\mathrm{Ta}-$ bela 1$)$.

Devido à flutuação populacional, o tamanho da amostra para análise do padrão de evolução dos índices PHP e IG, em um mesmo indivíduo, ficou bastante reduzida. Para uma análise comparativa somente quatorze internos geraram dados das variáveis ao longo do acompanhamento por quatro meses.

Esses quatorze participantes tinham idade média de 24,85 anos. Os índices PHP e IG na primeira análise foram 2,34 e 0,61, respectivamente. Nas avaliações seguintes o PHP foi 2,$08 ; 2,38 ; 1,91$

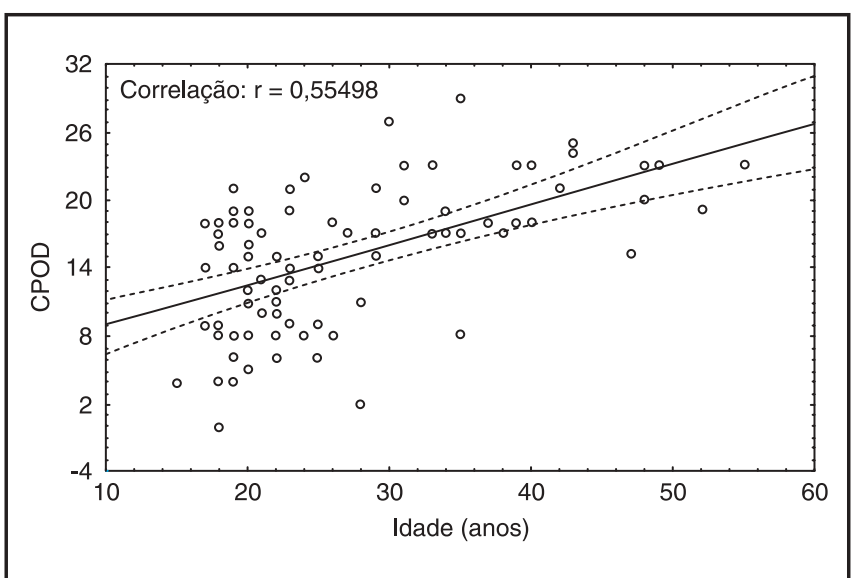

GRÁFICO 3 - Correlação entre o índice CPOD e a idade ( $\mathrm{p}<0,001$ - estatisticamente significante). Bauru - SP, 2000-2001.

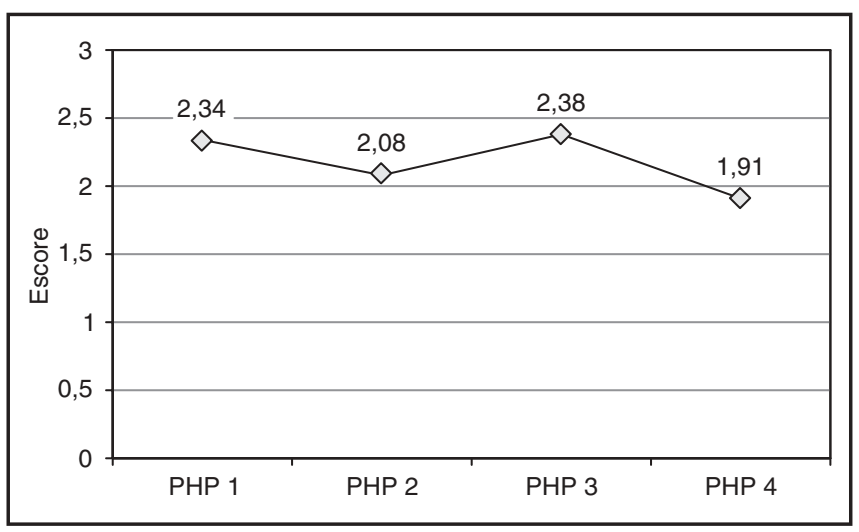

GRÁFICO 4 - Redução do índice de placa bacteriana (PHP). Bauru - SP, 2000-2001.

(Gráfico 4) e o IG foi 0,68; 0,63; 0,91, ambos respectivamente.

O fluxo salivar teve média de $1,31 \mathrm{ml} /$ minuto $(\mathrm{dp}=0,70 ; \mathrm{n}=97)$ na primeira medida. A maioria $(63,72 \%)$ apresentou fluxo salivar igual ou maior que $1,00 \mathrm{ml} /$ minuto (fluxo normal) (Gráfico 5). No segundo levantamento, após três meses, treze individuos foram reavaliados, obtendo-se um fluxo médio de $1,13 \mathrm{ml} /$ minuto, sendo que 53,84\% apresentaram fluxo salivar igual ou maior que $1,00 \mathrm{ml} / \mathrm{minuto}$; esses mesmos indivíduos mantiveram o fluxo salivar médio obtido na primeira análise, porém nesta, $69,24 \%$ tiveram fluxo salivar igual ou maior que $1,00 \mathrm{ml} /$ minuto (Gráfico 6).

O IG e o PHP iniciais também apresentaram correlação positiva com $\mathrm{r}=0,30(\mathrm{p}=0,002$ - estatisticamente significante) (Gráfico 7).

A necessidade de tratamento e o nivel de importância atribuído aos dentes, quando correlaciona- 
Ribeiro EDP, Oliveira JA de, Zambolin AP, Lauris JRP, Tomita NE. Abordagem integrada da saúde bucal de droga-dependentes em processo de recuperação. Pesqui Odontol Bras 2002;16(3):239-245.

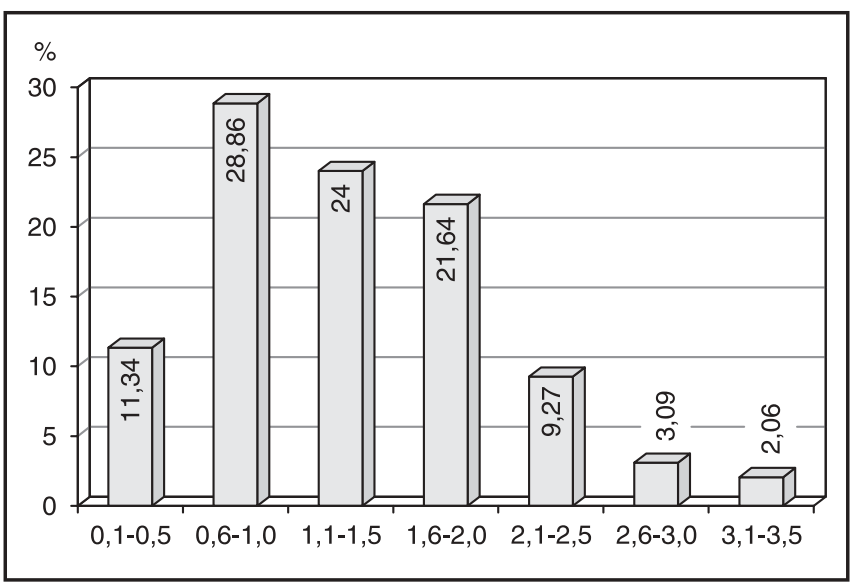

GRÁFICO 5 - Distribuição da amostra segundo o fluxo salivar inicial, em ml/minuto. Bauru - SP, 2000-2001.

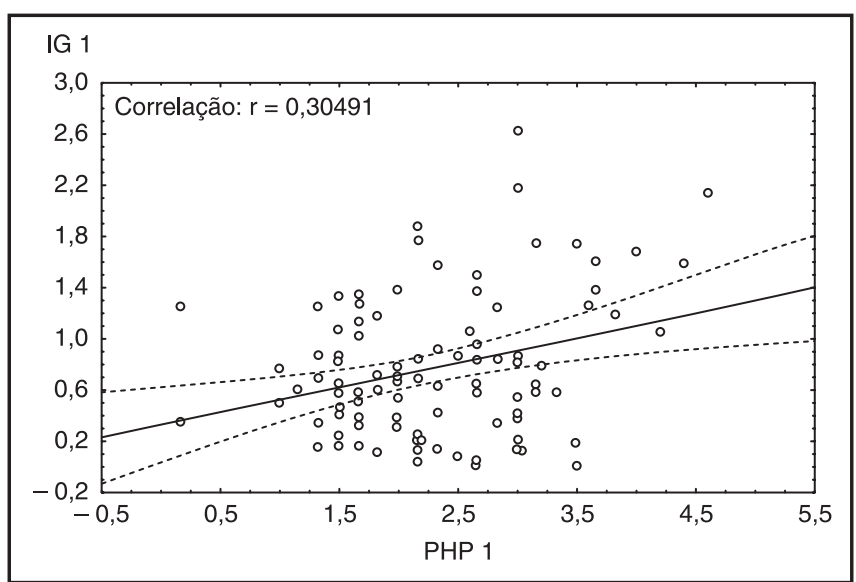

GRÁFICO 7 - Correlação entre o índice PHP 1 e o IG 1 $(\mathrm{p}<0,024$ - estatisticamente significante). Bauru - SP, 2000-2001.

dos, mostraram um $\mathrm{r}=-0,26(\mathrm{p}=0,019)$ (Gráfico 8).

\section{DISCUSSÃO}

A dependência de drogas é um problema de destaque social, com implicações sociais e orgânicas. É considerada um distúrbio, e por isso deve receber um enfoque mais amplo, envolvendo cuidados especiais no tratamento médico-odontológico.

As drogas têm efeitos diretos sobre as estruturas da boca (mucosa, dente, língua), sendo a cárie e a doença periodontal doenças de elevada prevalência em drogaditos, além da ocorrência de leucoplasias e carcinomas.

Quanto ao aspecto social, o uso de drogas causa alterações comportamentais nos indivíduos, com alteração do humor e perda da auto-estima,

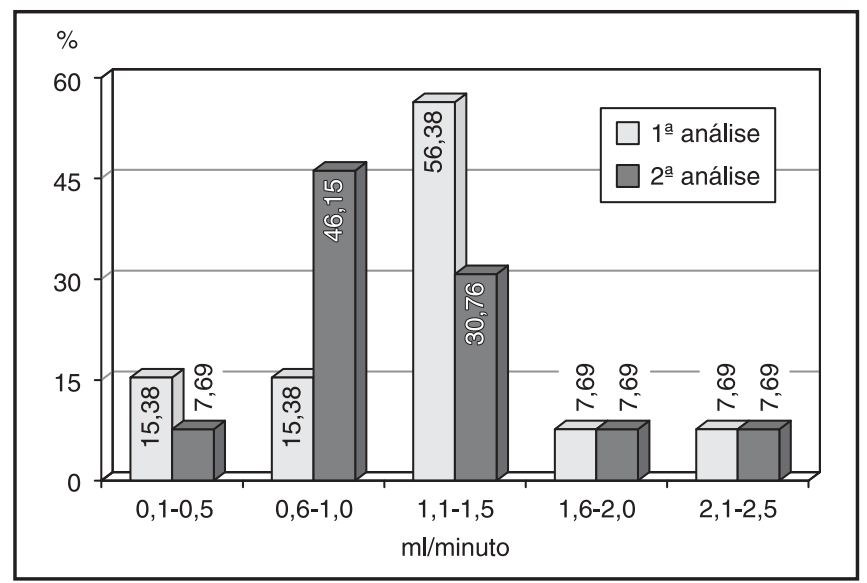

GRÁFICO 6 - Distribuição da amostra $(\mathrm{n}=13)$ segundo o fluxo salivar ( $\mathrm{ml} / \mathrm{minuto}$ ) em primeira e segunda análise. Bauru - SP, 2000-2001.

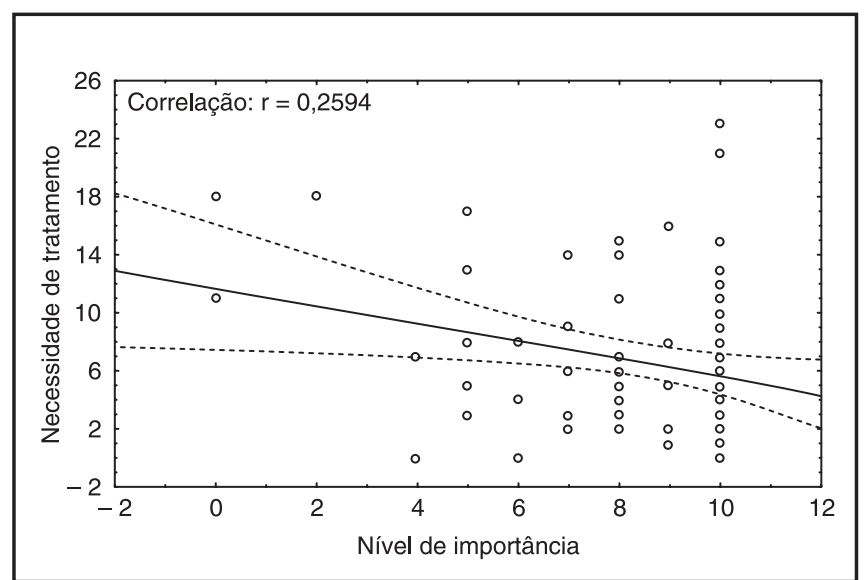

GRÁFICO 8 - Correlação entre a necessidade de tratamento e o nivel de importância dado pelo paciente à saúde bucal ( $p=0,021$ - estatisticamente significante). Bauru - SP, 2000-2001.

levando a um descuido com a saúde geral e bucaI $^{6,8,10}$. Além disso, a dependência química causa efeitos deletérios progressivos sobre a saúde sistêmica ${ }^{10}$.

Diante disso, o indivíduo que se encontra em processo de recuperação deve ser tratado integralmente, associando-se aos cuidados médicos e psiquiátricos, uma abordagem educativa para valorização da saúde bucal e dos cuidados necessários para manter a integridade das estruturas bucodentais.

Neste estudo, verificou-se que a higiene bucal dos internos era, em geral, deficiente com predominância do hábito de comer entre as refeições, especialmente balas, chicletes e chocolates, em concordância com os achados da literatura ${ }^{3,7}$. Telivuo et al. ${ }^{19}$ (1995) observaram um maior consumo de 
Ribeiro EDP, Oliveira JA de, Zambolin AP, Lauris JRP, Tomita NE. Abordagem integrada da saúde bucal de droga-dependentes em processo de recuperação. Pesqui Odontol Bras 2002;16(3):239-245.

açúcar no chá e café em fumantes diários quando comparados aos não-fumantes.

O dado encontrado de que $69,60 \%$ não apresentavam o hábito do uso diário do fio dental, está em concordância com relatos de Szymaniak et al. ${ }^{15}$ (1990). Estes relataram que droga-dependentes apresentam o sistema estomatognático mutilado pelo aparente descaso com a saúde bucal, refletida na baixa freqüência de uso do fio dental. No presente estudo, observou-se inflamação mais acentuada nas papilas proximais pelo maior acúmulo de placa bacteriana nas faces proximais dos dentes. Por este motivo, nas palestras enfatizou-se a importância do uso do fio dental e como usá-lo corretamente, além da distribuição de kits contendo fio dental, após as atividades educativas.

Kranzler et al. ${ }^{8}$ (1989) ressaltam que o maior risco de cárie destes pacientes pode ser explicado pelo menor número de visitas ao cirurgião-dentista. Isso fica evidenciado ao observar que $31,37 \%$ da população estudada não consultava o profissional odontológico há mais de vinte e quatro meses.

A média do PHP para os quatorze indivíduos que tiveram quatro avaliações consecutivas apresentou redução. Em função do tamanho da amostra, à análise de variância, esta redução não foi estatisticamente significante $(F=2,52 ; p=0,072)$, porém como reflexo do programa preventivo-educativo observou-se decréscimo da placa bacteriana (Gráfico 4).

Analisando-se o índice gengival desses mesmos quatorze indivíduos, observa-se um acréscimo de $49,18 \%$ no último levantamento em relação ao primeiro, não estatisticamente significante $(F=2,10$; $\mathrm{p}=0,116)$. A maioria dos participantes apresentava problemas periodontais e para que um tratamento periodontal apresente bons resultados, deve ter como base a raspagem para eliminação dos irritantes locais. Assim, é notável que o programa de educação tenha apresentado baixa eficácia em promover uma redução no IG, mostrando a necessidade de uma intervenção direta.

O fluxo salivar apresentou-se normal. Embora diversos trabalhos citem a xerostomia como um efeito das drogas ${ }^{5,7,11}$, esta não foi observada na maioria dos indivíduos. Possivelmente, após a interrupção do uso da droga, as glândulas salivares tenham a função normalizada e o fluxo salivar se restabeleça. Isso explicaria o resultado da primeira coleta de saliva em que $63,72 \%$ dos examinados apresentaram fluxo salivar igual ou maior que $1,00 \mathrm{ml} /$ minuto.

Entretanto, na segunda medida, apenas 53,84\% apresentaram fluxo salivar igual ou maior que 1,00 $\mathrm{ml} /$ minuto. Esses resultados geram discussões sobre o efeito imediato e a longo prazo da interrupção do uso das drogas. Além disso, por questões normativas da instituição, não se teve acesso ao tipo de droga utilizada pelo paciente, dificultando uma análise mais específica do efeito de cada droga sobre a condição salivar.

O alto CPOD observado $(14,88)$ está de acordo com a literatura ${ }^{1}$. Entretanto, deve-se ressaltar que o CPOD na população adulta é elevado e o que o diferencia nos drogaditos é a maior proporção de componentes cariados ou perdidos, reflexo tanto do reduzido acesso à assistência odontológica quanto da reduzida auto-estima.

A correlação negativa entre o nivel de importância dada aos dentes e a necessidade de tratamento mostrou que têm maior necessidade de receber tratamento odontológico aquelas pessoas que conferem menor importância à saúde bucal. Isto ocorre por uma higiene bucal mais precária ou por procura ao cirurgião-dentista com menor freqüência.

Uma peculiaridade deste estudo foi a característica de mobilidade da população estudada. Tal fato gerou a necessidade de maior atenção para que os assuntos abordados nas palestras não fossem repetitivos a ponto de gerar desinteresse e ao mesmo tempo pudessem atingir os novos ingressantes no programa.

Frente ao desafio colocado, de desenvolver um programa de atenção à saúde bucal de um grupo especial com enfoque à educação e prevenção, este estudo longitudinal comprovou a eficácia da presente proposta.

\section{CONCLUSÕES}

Este estudo mostrou que os internos da instituição Esquadrão da Vida, Bauru - SP têm, em geral, precária saúde bucal, como reflexo da drogadição, apresentando correlação negativa entre a necessidade de tratamento (dado objetivo) e a valorização da saúde bucal (dado subjetivo). O programa educativo-preventivo proposto reduziu o índice de placa bacteriana (PHP) e o fluxo salivar, após a interrupção da drogadição, mostrou padrões satisfatórios.

\section{AGRADECIMENTOS}

À THD Marta Regina Liporacci Aoki, pelo preparo do material utilizado; aos acadêmicos Ricardo Henrique Alves da Silva e Renato Yassutaka Faria Yaedu, pela colaboração no desenvolvimento das atividades e ao Esquadrão da Vida de Bauru, nossa gratidão por permitir a realização do estudo. 
Ribeiro EDP, Oliveira JA de, Zambolin AP, Lauris JRP, Tomita NE. Abordagem integrada da saúde bucal de droga-dependentes em processo de recuperação. Pesqui Odontol Bras 2002;16(3):239-245.

\section{REFERÊNCIAS}

1. Angelillo IF, Grasso GM, Sagliocco G, Villari P, Dérrico MM. Dental health in a group of drug addicts in Italy. Community Dent Oral Epidemiol 1990;19(1):36-7.

2. Bullock K. Dental care of patient with substance abuse. Dent Clin North Am 1999;43(3):513-26.

3. Carter EF. Dental implications of narcotic addiction. Aust Dent J 1978;23(4):308-10.

4. Darling MR, Arendorf TM. Review of the effects of cannabis smoking on oral health. Int Dent J 1992;42(1):19-22.

5. Di Gugno F, Perec CJ, Tocci AA. Salivary secretion and dental caries experience in drug addicts. Arch Oral Biol 1981;26(5):363-7.

6. Dunkley RP, Carson RM. Dental requirements of the hospitalized alcoholic patient. J Am Dent Assoc 1968;76(4): 800-3.

7. Friendlander AH, Mills MJ. The dental management of the drug-dependent patient. Oral Surg 1985;60(5):489-92.

8. Kranzler HR, Babor TF, Goldstein L, Gold J. Dental pathology and alcohol-related indicators in outpatient clinic sample. Community Dent Oral Epidemiol 1989;18(1):204-7.

9. Löe $\mathrm{H}$. The gingival index, the plaque index and the retention index systems. J Periodont 1967;38:610-6.

10. Meechan JG. Drug abuse and dentistry. Dent Update 1999;26:182-90.

11. Miers DR, Smith DP. Guidelines for treatment of recovering chemically dependent patients. J Am Coll Dent $1989 ; 56(1): 4,6,8$.
12. Ratcliff JS, Collins GB. Dental management of the recovered chemically dependent patient. J Am Dent Assoc 1987;114(5):601-3.

13. Scheutz. Dental health in a group of drug addicts attending an addiction-clinic. Community Dent Oral Epidemiol 1984;12:23-8.

14. Scoop IW, Heyman RA, Goldberg MA, Croy DJ. Dryness of the mouth with use of traquilizers: chlorpromazine. J Am Dent Assoc 1965;71(1)66-9.

15. Szymaniak E, Dymkowska W, Waszkiel DR. The condition of teeth and the need for treatment in drug addicts. Czas Stomatol 1990;43:134-9.

16. Pedreira RHS, Remencius L, Navarro MFL, Tomita NE. Condições de saúde bucal de drogaditos em recuperação. Ver Odontol Univ São Paulo 1999;13(4):395-9.

17. Podshadley AG, Haley JK. A method for evaluating oral hygiene performance. Publ Health Rep 1968;83: 259-641.

18. Tomita NE, Consulin TE. Programa educativo em saúde bucal para droga-dependentes em processo de recuperação. Odontologia e Sociedade 2000;2(1/2):33-9.

19. Telivuo M, Kallio P, Berg M, korhonen HJ, Mustomaa H. Smoking and oral health: a population survey in Finland. J Public Health Dent 1995;55(3):133-8.

20. World Health Organization. Oral health surveys: basic methods. $4^{\text {th }}$ ed. Geneva: ORH/EPID; 1997. 